\title{
A Note of Appreciation for Ullrich Kockel
}

\author{
Gabriela Kiliánová, Rūta Muktupāvela, Philip McDermott, \\ Marion Demossier, Alessandro Testa, \\ Alastair McIntosh and Thomas M. Wilson
}

The success of an academic journal depends on many factors. Let us, however, only mention two of them: its high-quality editing and its continuity. The Anthropological Journal of European Cultures is prosperous because it fulfils both of these criteria. This means it has been published periodically, nonstop for nearly three decades under the supervision of editors with significant dedication to the journal.

In 1990, the founding editors Ina-Maria Greverus and Christian Giordano started an ambitious project of a new journal. Their wellconsidered concept of $A J E C$ aimed at changes in European cultures from an anthropological perspective and also at the creation of a discussion forum crossing disciplinary boundaries. From the very beginning they also introduced thematic foci for every issue, and this editorial programme became one of the defining characteristic of the journal. Despite financial and publishing difficulties, AJEC developed into a recognised journal throughout the nineties, bringing innovative topics to the public as well as remarkable research results concerning social transformations of European societies in particular.

When Ina-Maria Greverus stepped down as editor in 2001, the journal adopted a new collaborative editorial policy. The thematic foci were discussed among the members of the newly established international editorial board, and the board members and invited experts prepared the corresponding journal issues. This policy was successfully maintained for several years until it gradually reached its limits of human and financial resources. Therefore, on behalf of the editorial board, Helena Wulff proposed to Ullrich Kockel the position of editorin-chief in 2006. AJEC became a Berghahn journal and, under Ulli's editorship, one of the most important European anthropological periodicals in the cogent scientific fields of anthropology and ethnology. Currently, the journal can build on its success by further developing its concept to function as a critical forum for ethnographic research on European societies. 
Thank you, Ulli, for your excellent journal editing and for maintaining the continuity of $A J E C$. I wish you all the best.

Gabriela Kiliánová

Slovak Academy of Sciences, Bratislava, Slovakia

$$
* * *
$$

First of all, let me thank the new editorial team of AJEC, namely Elisabeth Timm and Patrick Laviolette, for the wonderful idea as well as for the possibility and privilege to express my gratitude to an outstanding personality, scientist and friend - Professor Ullrich Kockel.

I am not going to mention all his good deeds in the broad field of ethnology, economic anthropology, heritage tourism, countercultural movements, intercultural philosophy and so forth, as they are already reflected in his curriculum vitae. I would rather think of Ullrich Kockel as a bright and extraordinary scholar and would comment on three equally significant and interrelated dimensions - a researcher, an author/editor, a human.

My first notion of Ullrich Kockel as a scientist and leader of a prominent community of ethnologists was in the context of SIEF, where I participated in congresses and workshops, as well as in his Place Wisdom study group. I had the possibility to appreciate his high professionalism while getting acquainted with his activity in the strategic leadership group for the national research programme 'Sustainability of Latvian Cultural Traditions in an Innovative Environment. Habitus' (Latvian Academy of Culture, 2014-2018), delighted by his keynotes, as well as working together in the Horizon 2020 project 'CoHERE. Critical Heritages: Performing and Representing Identities in Europe', where he has been guiding one of the work packages.

When characterising Professor Kockel as a scientist, in my opinion, it would be important to mention his characteristic trait - namely, the ability to combine inquisitiveness and an analytically critical mind with emotional intelligence as well as a rational and analytical attitude towards empiricism with deep respect towards the mentality and values of the subjects of his research - these are rather rare qualities nowadays. He is not simply a generator of new knowledge; he is enhancing cleverness, which is rooted in systematic, detailed observations and scrupulous analyses of sources. He is creating phronesis, or wisdom, so very necessary in our era of an end-in-itself philosophies and information chaos. The wisdom of Ullrich Kockel is deep and 
multisited. It is logical, based on facts and research as well as delicate and warm, based on the ability and skill to appreciate the reality very personally and with empathy. Besides, he has the ability to appreciate authenticity and beauty in all - in words, sounds, movements, figures and even in numbers - as well as to revert it to scientific discourse, to create new extraordinary ideas, to fascinate his students with them, thus giving impetus to the new generation of researchers. If a scholar can be characterised as a person doing what he likes best and, besides, receiving a salary, then this is about Professor Kockel!

The keywords characterising him as an editor, to my mind, are explicitness of thought, excellent feeling for the language, openness and deep respect towards the author. From my experience while cooperating with him, I can assure the reader that he has the ability to distinguish things not always distinguished by the author himself. It is very significant for me as a non-native English speaker that he can motivate and substantiate rather than destroy and demonstrate one's superiority. He can thus brighten and outline the author's main ideas. Indeed, he finally makes me love my own text in English!

While reflecting on Ullrich Kockel as a human and friend, it is impossible for me to think of him without his wife - a mate of his thoughts, works and life, Professor Máiréad Nic Craith. They are together a fascinating academic couple working in tandem frequently, inspiring not only with their highest level of scientific activity but also with their harmonising presence everywhere - be it a conference hall or a nice and cosy friends' get-together. Ullrich and Máiréad both possess a kind of magnetism that breaks down the hierarchy, helps build self-confidence and, at the same time, helps somebody think and judge critically. This feature, above all, often makes their colleagues, students and friends find a meaning to their research activities. Such personalities push forward to search persistently for truth, not to stop at temporary achievements, and to strive for realising new goals. I thank both of them for this. With deep respect and gratitude.

Rūta Muktupāvela

Rector of the Latvian Academy of Culture, Riga, Latvia

$$
* * *
$$

I was fortunate enough as a then postgraduate researcher to have been involved in the excitement leading up to the 2008 SIEF International Congress in Derry, Northern Ireland, convened by Professor Ullrich 
Kockel. The theme settled upon for that event was 'Liberating the Ethnological Imagination'. I can think of no one who personifies that perspective more than Ulli, a true champion of his discipline whilst never being afraid to reach across the arts, humanities and social sciences. Indeed, this theme might characterise Ulli's editorship of the Anthropological Journal of European Cultures.

Ulli's work reflects a deep passion for people's experiences at the local whilst acknowledging their entanglement in the wider global web. This passion became clear under his tenure as editor of $A J E C$. As we know, $A J E C$ serves as an important forum for research in, on and about Europe. Ulli has ensured that we continue to focus on places and spaces not as narrowly defined geopolitical entities but rather as cultural constructions through people's experiences and manifested in their lives.

When I think of this focus, Ulli's work on space, place and borders instantly springs to mind. His ground-breaking dissection of the lived experiences of people in contested borderland spaces and its associated critique of the political hierarchies is as relevant today as ever and clearly shaped the journal's direction. We know all too well in the Europe of 2019 that places, spaces and borders matter and have the potential to consolidate division and inflame tensions. The aforementioned SIEF conference in 2008 was held just a few miles from the Irish border, which has proven so problematic to the political hierarchies of Europe. This provides just one example of the continued necessity of the 'ethological imagination'. Ulli, however, has left us in a very good place at $A J E C$ to continue to interrogate these questions as they continue to have huge relevance in the Europe of today.

Philip McDermott Sociology, Applied Social and Policy Sciences, Ulster University, Belfast

Ulli stands out amongst that rare breed of scholars who combine eclecticism with a genuine cross-disciplinary, encyclopaedic knowledge (meaning here University of Life) - something he even combines with an ability to think outside the box. I was lucky enough to meet him in the 2000s through a colleague, Dr Sarah Blowen, when he was appointed to a Chair of European Studies at the University of the South West of England in Bristol. What sparked our common interests, beyond a passion for ethnology, was the cross-disciplinary platform provided by the development of European ethnologies at 
the time and the increasing focus upon local communities, heritage, place and sustainability.

Ulli, through his continual encouragement and his unconditional support, inspired me to reflect back upon my hybrid position as a French anthropologist, trained in the French ethnological tradition, working in a European studies department in the UK. Ulli had reinforced my passion for anthropology both as a scholar and as a friend. He has inspired me and, I am sure, many others to stick with ethnography as a means of exploring the world we live in, and he has also made sure that my contribution was recognised beyond the world of French or European studies. His major contribution to our field lies in his innovative studies of the relationship between culture and economy.

When appointed to a chair of French and European studies in 2012 at the University of Southampton, Ulli was again here in his supporting role. Naturally I asked him a few years later, to his surprise, to chair my inaugural. More recently our paths have crossed again in the context of his contribution to COHERE (Critical Heritages, an EU funded project) as member of the School of Social Sciences at Heriot-Watt University. Ulli is a model of academic professionalism and collegiality, and I hope that when it is time for us to meet again and have a drink with the best bottle of Burgundy wine I can find, I will be able to thank him for everything. Many best wishes!

Marion Demossier Dept. of Modern Languages Ë Linguistics, Southampton University, UK

Long before starting a still recent but already fruitful scholarly collaboration with him, when I still was a PhD student, Ullrich Kockel was 'just' the name of one of the many ethnologists of Europe I was avidly reading at the time. Shortly afterward and gradually that name started to materialise into a familiar figure, one I was to see often at conferences (SIEF, EASA, ACHS).

I remember the first time we talked: it was a sunny day in late June during the SIEF conference in Zagreb in 2015. I was casually standing outside a bar, and inside Ulli was sipping a coffee. There was no mutual acquaintance in sight and, hence, nobody to function as an intermediate. So I gathered some courage and decided to go and introduce myself. He looked puzzled and slightly annoyed at first - I guess that's the look experienced scholars must assume when addressed by petulant 
youngsters - but we soon managed to break the ice. In fact, Ulli might not seem the most friendly creature (especially for a then very young postdoc in search of broader recognition), but behind that somewhat intimidating half-academic, half-picaresque appearance lies, in reality, a very cordial nature. Since then we have been successfully collaborating on publications and in the editorship of $A J E C$.

With reference to the latter, I can still remember the moment, a couple of years ago, in Göttingen, when bumping into me at a crossroads, he, taking good care that I could overhear him, pointed at me and mumbled to Máiréad: 'He does not know yet, but he is going to be the new review editor of $A J E C$ ' (I had in fact sent my application for that position some time before). These are nice memories, and sharing them with the readership of $A J E C$ is my personal way of thanking Ulli for having produced a rich scholarship over the years, for the excellent job done with $A J E C$, for his trusting the obscure young scholar I was in 2017 (and the even obscurer one I was in 2015), for his support and friendliness and for confirming my conviction that, no matter how intimidating your interlocutor might seem, informal drinks and chats at conferences are still the best way to get away with being a young academic.

\section{Alessandro Testa \\ Charles University Prague, Czech Republic}

$* * *$

I have been contemplating the text of Ulli's inaugural lecture, Making Sustainable Development Relevant 'on the Ground', at Heriot-Watt University, in addition to having attended the event on Halloween's Day, 2018. About the need to explore 'authenticity' to deepen community but in ways that avoid feeding authoritarian populism, it reaffirms all my experience of him - namely, a warm benevolence of mind and a way of doing and applying ethnography that opens up wise ways for being human around the challenging issues of identity and belonging. Both he and Máiréad have made this ethos central to their lives. They are scholars of both head and heart, who have given generously to their students. We are grateful. 
Ulli Kockel is a rare teacher and scholar. I have known him for thirty years, since his days at the University of Liverpool, and I have been consistently impressed, sometimes surprised, by his breadth of interests in most things European (regional, economic and cultural) as well as German and Irish, all driven by an intellectual curiosity and social awareness that, in his modesty, puts many other academics to shame. His most particular attribute is his generosity - of time, energy and scholarship - a generosity that has not only helped motor AJEC but also equally influenced dozens, perhaps hundreds of colleagues in the North and West of England, Ulster and Scotland. Additionally, there is one other achievement that always impressed me: Ulli's Cork accent when speaking English, which may now be softened in his new environment, but I pray is not gone.

Thomas M. Wilson Dept. of Anthropology, Binghamton University, Vestal, USA 